\title{
Interactions Between Knowledge Sharing and Organizational Citizenship Behavior
}

\author{
Yavuz Demirel, Zeliha Seçkin, Mehmet Faruk Özçınar \\ Aksaray University, Aksaray, Turkey
}

\begin{abstract}
Recently, researches toward the social and psychological structure of organizations have proliferated observably. As the quality and quantity of these studies improve, the value of such issues gets more manifest. In this context, efforts toward making employees' knowledge, which is an indispensable value for organizations, accessible and efforts to make it available for work processes and social relations extend new behavioral patterns. Organizational citizenship behavior is an example of such patterns. This paper attempts to explain and discuss interactions between organizational citizenship behavior and knowledge sharing, which is reasoned to have a defining role over it, and to draw attention on the issue. Organizational knowledge sharing, the factors influential on it, and the relationships between the antecedents of organizational citizenship behavior and knowledge sharing are being dwelled upon conceptually.
\end{abstract}

Keywords: knowledge, knowledge sharing, organizational citizenship behavior

\section{Introduction}

The key capital and locomotive power of organizations is "human", which is a social being. Thus, the existence of workers who have adopted the organization's values, who see the organization's purposes as their own purposes, and who make an effort more than expected in the organization with willingness is becoming more important for the organizations, so that they can carry out their activities and achieve their goals. When the studies on organizations conducted in recent years are looked at, it will stand out that interest in psycho-social issues, which were formerly going unnoticed though they are crucial for organizations, has grown. An outstanding example of such issues is organizational citizenship behavior. Organizational citizenship behavior involves the organization members' behaviors that include positive actions. In other words, it is the behaviors of the workers that are demonstrated voluntarily without any expectations and beneficial for the organization. Findings of studies on the subject have revealed that workers who tend to demonstrate organizational citizenship

Yavuz Demirel, Ph.D., Associate Professor, Department of Business Administration, Faculty of Economics and Administrative Sciences, Aksaray University.

Zeliha Seçkin, Ph.D., Assistant Professor, Department of Administrative and Economical Programs, Ortaköy School of Vocational Studies, Aksaray University.

Mehmet Faruk Özçınar, Ph.D., Assistant Professor, Department of Public Administration, Faculty of Economics and Administrative Sciences, Aksaray University.

Correspondence concerning this article should be addressed to Yavuz Demirel, Aksaray University, Faculty of Economics and Administrative Sciences Department of Business Administration, 68100 Aksaray/Turkey. E-mail: ydemirel75@gmail.com. 
behavior are more efficient and productive, prone to teamwork, enthusiastic for full participation and knowledge-sharing, and have higher levels of loyalty and responsibility.

In order for the workers to demonstrate organizational citizenship behavior, it seems necessary to build a culture of communication, trust and knowledge sharing. Organizational citizenship behavior and knowledge sharing are not expected to meet the prospects in a working atmosphere where suspicion and uncertainty reign. The sense of organizational citizenship behavior can be positive or negative, depending on the workers' perceptions of organizational knowledge sharing. The positive perception among the workers that knowledge sharing is supposed to generate is an important factor for determining the tendency of the workers toward organizational citizenship behavior. Consequently, this study grounds on the principle that workers cannot be forced, but they can share knowledge depending on behaviors that are not pre-defined, and it is beneficial for the social system of the organization. The conceptual relationship and interaction between organizational knowledge sharing and organizational citizenship behavior is analyzed in detail.

\section{Organizational Knowledge Sharing: Concept and Content}

Knowledge, which has become the most powerful tool for surplus value, produces more value when it is shared. This fact has caused the "Knowledge is power" (Liao, Chang, Cheng, \& Kuo, 2004, p. 24) aphorism of Bacon to be moved one step further as "Knowledge sharing is power" (Gurteen, 1999, p. 3). In this respect, it can be pronounced that knowledge is doubtlessly among the most strategic and important resources for organizations (Fei \& Chen, 2007, p. 2), and not simply a rhetorical expression. Knowledge sharing functions as a fundamental element that contributes to the competitive power of the organization in the global market, improves management-worker relations, and increases the performances of the employees. Consequently, as long as knowledge is shared in an organization, that organization will gain competitive advantage. Sharing requires the circulation of knowledge. The boundaries of this circulation are drawn not only by technology, but also depending on the behavioral factors of the employees (Liao et al., 2004, pp. 24-25). The view of Cheah and his colleagues (2009, p. 1423) that knowledge sharing is an activity and knowledge is transmitted by this action corresponds to the studies of Liao and his colleagues. Takeuchi (1995) also considers the production of knowledge as a process and emphasizes that production of knowledge cannot take place without the individuals by drawing attention to the importance of individuals in this process, and he points to the importance of knowledge sharing in enabling organizational effectiveness. According to Lin (2008, p. 241), whereas knowledge sharing improves the competitive power of an organization, the lack of knowledge sharing can cause serious trouble for the organization. Active knowledge sharing is related to how willing and prone to sharing knowledge the employees are (Fei \& Chen, 2007, p. 3) and how enthusiastic they are (Vries \& Hooff, 2006, p. 116). The development of knowledge sharing arises from the active external relations among the employees, shareholders, intermediates and customers and it is transformed to organizational strategies that will enable to organization to gain competitive power in the future. However, Batt has reached the conclusion that an organization cannot compel the employees to share tacit knowledge. Nevertheless, it is indispensable for the knowledge managers to put forward incentives and rewards that will encourage the employees to contribute to knowledge sharing and the information pool. According to Gagne (2009), knowledge sharing is a process when the employees exchange knowledge and produce new knowledge. However, the fact that organizational 
knowledge sharing generates value requires the reproduction of knowledge at personal and organizational levels. Considering this fact, it is necessary for the managers to set up systems that will motivate the employees to share knowledge positively and willingly. The result of this motivation is related to how important the employees consider knowledge sharing with a personal or collective purpose (Gagne, 2009, p. 572). In other words, individuals or groups need to share knowledge with each other through cooperation and therefore gain mutual benefits. In their study, Small and Sage (2005/2006) offer three explanations for the dilemma of why employees tend to/need to share knowledge in spite of the fact that they will lose power and profit: gaining knowledge, reusing knowledge and the aspiration to produce knowledge.

Although knowledge sharing creates personal and organizational value, it may not always occur in an ideal way for every organization. It must not be ignored that there are factors of secondary importance in the resolution of the mentioned conflict. The term knowledge sharing also represents a dilemma between personal benefit and organizational benefit. In terms of organizational benefit, knowledge sharing is indispensable whereas it can be seen as a behavior that can cause negative effects for the individual. Knowledge sharing will increase the possibility of an individual or a group to provide benefits to another individual or group that will become a rival in the future. Therefore, organizations that foresee the fact that individuals will avoid knowledge sharing, introduce certain systems of incentives and rewards in order to prevent this and to ensure knowledge sharing in the organization (Liao et al., 2004, p. 25). These systems of incentives and rewards should not be considered different from technological tools in terms of overcoming the dilemma between personal and organizational benefits. Knowledge sharing is also related to the degree of trust among the shareholders. As Bratianu and Orzea (2010, p. 108) indicated, most people will avoid their knowledge and experience when they do not have a certain degree of trust for their interlocutors. When people share a certain piece of knowledge, they need to be assured that it will not be misused. In this case, we can say that knowledge sharing, and flow and transfer of knowledge will occur more frequently in organizations and working units where there is high level of sense of trust. In this respect, plenty of research that supports the relationship between trust and knowledge sharing has been carried out (Nita, 2008, p. 16; Yücel \& Samanc1, 2009, pp. 116-117). It must not be forgotten that when people believe that knowledge is the source of power and prestige, knowledge sharing will cause the individuals to be afraid to lose power and therefore it will negatively affect knowledge sharing. Moreover, individuals will think that a decline in their power and status will cause their perceived value in the organization to decrease and they will fear becoming expendable. Studies that have been carried out so far confirm that knowledge sharing provides benefit for everyone except the one who shares the knowledge. This, therefore, means a decrease in the personal value of the individual who contributes. Riege (2005, p. 23-25) considers the problem of knowledge sharing that is assumed to arise from various reasons as an "obstacle" and suggests three dimensions of the concept which are personal, organizational and technological. Knowledge sharing obstacles at employee and individual level are the lack of communication and social bonds among the employees, differences in national culture, too much emphasis on the position, lack of time and trust. On the other hand, obstacles at organizational level are economic capacity, lack of background and resources, lack of formal and informal meeting places, inconvenient physical environment. Technological obstacles are insufficient or no technological devices, the fact that these devices are not used for the purpose of sharing knowledge among the employees and not being able to follow technological advancements. In addition to these factors, difficulty to transform personal knowledge into organizational 
knowledge represents another important obstacle in knowledge sharing. Kankanhalli, Tan and Wei (2005) suggests that transforming personal knowledge into organizational knowledge can be difficult in the following ways:

- Discouraging organizational climate and the motivational lack of the individuals;

- Tensions that may occur between efficient and inefficient knowledge cycles in different organizational levels;

- Compulsion in codification;

- Difficulties in the relationships.

According to Chow and his colleagues (2008), the effectiveness of knowledge sharing for the employees and the organization depends on organizational culture, performance evaluation, reward system and the use of information technologies. When we focus on the production and sharing forms of knowledge through the interaction between explicit and implicit knowledge, we come across four possible processes:

- Socialization: Sharing of tacit knowledge among individuals;

- Externalization: The appreciation of tacit knowledge and its transformation into easily understandable forms;

- Internalization: Transformation of explicit knowledge into tacit knowledge;

- Combination: Placing explicit knowledge into more complex explicit knowledge sets.

As tacit knowledge becomes explicit knowledge and creates surplus value, knowledge sharing becomes more important for the organization and individuals.

\section{Organizational Citizenship Behavior Concept, Its Dimensions and Its Importance for Organizations}

The highly competitive environment urges organizations to search for new ways of gaining sustainable competitive advantage. After it was found out that technological-, structural- and capital-based assets are insufficient for getting the desired result, attention was drawn to human factor. However, it is not enough for the employees to carry out the defined role requirements in order to gain sustainable competitive advantage. In this respect, organizational citizenship behavior (OCB), which is believed to increase the performance of the employees, and therefore the organization, is among the leading issues that draws the most attention in the fields of organizational psychology, organizational behavior and human resources. Although the term is attributed to Barnard (1938) and Katz (1964) (Tayyab, 2005, p. 49; Organ et al., 2006, pp. 44-51; Sezgin, 2005, p. 320; Farh, Zhong, \& Organ, 2004, p. 241), it became popular in the literature through the papers of Organ and Bateman in the "42nd National Management Conference" in 1982 and their studies afterwards (Podsakoff, Mackenzie, Paine, \& Bachrach, 2000, p. 513; Karaaslan, Ergün, \& Kulaklığlu, 2009, p. 138). Barnard called attention to the willingness of the employees to contribute to the organization with their efforts, and Katz put emphasis on the importance of extra role behaviors that were neither considered compulsory by the managers nor predefined. The well accepted definition of OCB is attributed to Organ (Yener \& Akyol, 2009, p. 258). According to Organ (1988), OCB is "the voluntary behaviors of the individual that are not directly and clearly defined by the formal reward system of the organization, but help the organization work effectively and efficiently as a whole". Knowsky and Pugh (1994) define the term as the voluntary behaviors of the employees that are independent from 
the formal reward system and beyond the role definitions. According to the definition of Blakely (2003), OCB is a pattern of behaviors that are different from the technical efforts required by the job and add surplus value to the activities related to the work being done in psycho-social terms. Van Dyne and his colleagues (1995) define OCB as voluntary behaviors that go beyond defined job expectations and performed with the intention to provide benefit for the organization. Briefly, OCB involves all the positive voluntary actions of the employees that are related to the behaviors of the organization members and are performed for the benefit of the organization. (Jahangir, Akbar, \& Haq, 2004, p. 76).

It is possible to evaluate the work attitudes of the employees in terms of OCB in two dimensions. The cognitive dimension that is towards the features of the attitude object and affective dimension that is towards the attitude object. Both dimensions are known to affect OCB in a positive way. When it is considered that OCB depends on the desires, voluntary efforts and sincere actions, it will be better understood how important individuals act "voluntarily" affectively and cognitively. In other words, individuals do not act in this way due to professional duties (Sezgin, 2005, p. 320). Therefore, in the case of a performance evaluation of the employees, a two-dimensional process will need to be taken into consideration: In-role and extra-role performance. In-role performance involves behaviors that employees are expected to perform by the organization, that exist in their formal job descriptions and that are directly or indirectly related to the mission of the organization. Extra-role behavior, on the other hand, involves behaviors that support the organization but do not exist in the job description of the employees, and behaviors that are voluntary, and different from the job role. Examples of these behaviors are cooperation among the employees, voluntarily undertaking extra responsibility, orientation of the new employees, willingness to help others succeed in their work, and doing more work than they are required by the job (Bergeron, 2007, p. 1078; Chen \& Chiu, 2009, p. 476; Zellars, Teper, \& Duffy, 2002, p. 1068). These behaviors include positive and voluntary behaviors as they are independent from the formal reward system and their repudiation is not subject to a penal enforcement (Çetin, 2004, p. 128; Acar, 2006, p. 3; Finkelstein, 2006, p. 604). The definition of organizational citizenship behavior by Organ (1988) involves a structure consisting of the components below (Schlecter \& Engelbrecht, 2006, p. 3; Karaaslan et al., 2009, pp. 138-139).

- These behaviors go beyond the job requirements and formal job descriptions of the employees. They are out of the formal roles of the employees;

- These behaviors are voluntary by nature and employees decide to demonstrate these behaviors willingly. Thus, employees cannot be forced to perform these actions by the organization;

- These behaviors depend on the voluntary preferences of the employees as they are not defined by the formal reward system or the structure of the organization. Employees do not expect to get a reward in return for their extra efforts. Besides, they are not to be penalized because of the roles and behaviors that they do not perform in terms of $\mathrm{OCB}$;

- OCB is the whole set of behaviors that contribute to the employees and the organization.

In many studies on organizational citizenship behavior, there are differences among the numbers and classifications of the dimensions related to this behavior. Smith and his colleagues (1983) mention two dimensions related to OCB that they call altruism and generalized compliance (conscientiousness). Graham (1991), on the other hand, divides these dimensions into three, which are obedience, loyalty, and participation. While Williams and Anderson (1991) considered OCB in individual and organizational levels, Podsakoff and his 
colleagues (2000) and Karaaslan and his colleagues (2009) considered OCB in seven dimensions. On the other hand, Organ (1988) mentions five dimensions. Although there are various dimensions in the literature suggested by the researchers, Organ's five-dimensional classification is the fundamental one. These five dimensions are altruism, conscientiousness, courtesy, civic virtue and sportsmanship (Kays, 2001, p. 104; Tayyab, 2005, p. 51, Boiral, 2009, p. 224; Çetin, 2004, p. 19; Bolat \& Bolat, 2008, p. 79).

\section{Altruism}

It involves attitudes and behaviors that are related to helping other workers overcome the problems they encounter and contribute voluntarily to their performances and activities in this way. When an employee voluntarily helps another employee complete his/her work and succeed in an activity he/she cannot overcome, that is altruism. These behaviors that are intended to increase the performance of the colleagues also contribute to group efficiency and to the fulfillment of organizational goals thanks to the cooperative effect. Although altruism represents the individual efforts of the employees, it provides benefit for the organization on the whole.

\section{Conscientiousness}

It expresses the fact that the employees in an organization go beyond the requirements of their formal duties and roles and willingly contribute to the functioning of the organization as a whole. Behaviors such as the attendance of the employees to work, using time of work efficiently and effectively, performing work-oriented and target-oriented actions that require effort, abiding by the formal rules, protecting the resources of the organization, making suggestions that solve problems, etc., can be listed as examples of conscientiousness.

\section{Courtesy}

Courtesy involves the conscious behaviors of the employees that are preventive against the problems that may arise in the organization. In this respect, courtesy points to the fact that employees must act thoughtfully and carefully before performing actions that will affect the work they are doing and they must determine the problematic points beforehand and make the necessary efforts for resolution. It emphasizes the fact the employees need to act responsibly before performing actions that will affect their work. Courtesy-based informing and voluntary participation in efforts of knowledge sharing can be considered as an example in this respect. The dimension of courtesy, which contributes to the development of cooperation awareness among the employees, also has an effect on establishing the positive communication necessary for cooperation. Conscientiousness involves behaviors that are intended to prevent organizational problems.

\section{Civic Virtue}

It is the behaviors that are intended to protect the benefit of the organization at utmost level. It refers to the highest level of active participation in the organizational life. It involves the behaviors in terms of voluntary participation in organizational activities. Civic virtue also reflects a situation where commitment and interest in the organization is at the highest level. Behaviors such as actively contributing to the resolution of the problems by voluntarily participating in management, expressing ideas about the strategy that the organization should follow, voluntarily supporting the action of converting the threats for the organization into opportunities, performing actions and practices that will benefit the company can be considered relevant to civic virtue. Voluntary behaviors such as taking part in the social activities in the organization can be shown as an example of the civic virtue dimension of OCB. Being sensitive to the change occurring in the atmosphere of the organization 
and developing positive reactions, accessing knowledge and being willing to share this knowledge with colleagues also are involved in civic virtue dimension.

\section{Sportsmanship}

Sportsmanship involves behaviors such as being sensitive to the inconveniences, constraints and extra efforts caused by job requirements and process, not complaining about the job and other employees, protecting the positive attitude against negative occurrences, tolerating those who have different ideas, willingness to participating in group work, etc.. They are behaviors that require the skill of internalizing the understanding of not minding problems too much. Trying to avoid possible tensions in the organization can be considered an example of behaviors involved in sportsmanship.

Considering the dimensions representing OCB, it is understood that these behaviors depend on "willingness", which emphasizes the preferences of employees concerning OCB. Studies dealing with the effect of the state of mind and personality traits of the individuals on their preferences have been carried out. According to what Messer and White (2006, p. 67) cite from George, Carlson and their friends Isen and Daubman, it was found out that there was a positive correlation between the positive state of mind of the employees and altruism, and the employees were more willing to fulfill the formal and extra role requirements. Koys (2001) draws attention the fact that there are strong correlations between each dimension of organizational citizenship behavior and customer satisfaction. Besides, when the employees have strong organizational citizenship behaviors, the manager will be able to allow time for more important issues (Koys, 2001, p. 104; Bateman \& Organ, 1983, p. 588).

\section{The Relationship Between Knowledge Sharing and Organizational Citizenship Behavior}

These two terms have been the subject of the scores of diverse studies in the literature. The interest in the issue is growing particularly because of the fact that both terms occur as a result of interactions among the employees and they increase the performance. Whether organizations can achieve sustainable competitive advantage depends on the precondition that they must attain their defined performance/success aims. When the organizations achieve this, the need for the behaviors as part of OCB arises. In this respect, it is obvious that knowledge sharing will have a positive effect on the organizational performance directly or indirectly due to its definition. As Hendriks (1999, pp. 91-100) states, knowledge sharing is a very significant channel for transforming personal knowledge to a strategic source for the organization. Many studies are carried out without the need to explain the necessity and importance of knowledge sharing for an organization. However, it must be accepted that knowledge sharing is not a behavior that can easily be accomplished. Therefore, the ways of ensuring that the employees share knowledge have been studied. Ipe (2003) indicates that many researchers have handled the motivation for knowledge sharing as a function of reciprocity. Li and his colleagues (2010), who have made a recent study on this issue, have approached the issue on a cultural level and have focused on whether the organizational climate is suitable for knowledge sharing or not. This study focuses on OCB, which is a variable that must be considered to be relevant to the organizational climate and atmosphere. Naturally, neither knowledge sharing nor OCB is a phenomenon that is equally available in every organization. Thus, whether the level of OCB varies depending on the pervasiveness of knowledge sharing is a meaningful research subject. When the relationship between organizational citizenship behavior and trust within the organization (Wech, 2002, 
p. 354) is considered, naturally it will be assumed that there is a relationship between OCB and knowledge sharing. Connelly and Kelloway have found out that social interaction reinforces the perception of knowledge sharing culture but technology does not have such an effect, in their study where they evaluated various factors that possibly impinge on the perceptions of knowledge sharing culture in an organization (Connelly \& Kelloway, 2003, p. 298).

This finding show that not material factors but social and psychological factors and human relations are decisive in accomplishing knowledge sharing. OCB is a significant topic to be evaluated in this respect. There are studies, though in limited numbers, that measures the relationship between the two terms. Mogotsi (2009, p. 136) has reached the conclusion that there is a positive correlation between knowledge sharing and OCB and has reached the inference that knowledge sharing is a type of OCB. Connelly and Keloway (2003, p. 294) even concluded that knowledge sharing and OCB are similar behaviors. Lin (2008, pp. 242-243) has put forward the positive correlation between knowledge sharing and the dimensions of OCB in his research. Lin states that knowledge sharing is affected by altruism, conscientiousness, courtesy, civic virtue and sportsmanship, which are the dimensions of OCB, and discusses the relationship between these dimensions and knowledge sharing. Nevertheless, in such a case where knowledge sharing is the defined policy of the organization and it is included in the reward system (Sezgin, 2005, p. 320), there can be a difference in terms of the voluntary OCB actions of the employer. Much as the view that OCB must be supported by the reward system is emphasized, this situation bears the possibility of a conflict about OCB. Including actions of OCB in the reward system will not be in accordance with the understanding of "not being included in the reward system" which forms the essence of this behavior. In that case, whether employees perform actions of OCB for reward or for the sake of OCB spirit will need to be discussed. Furthermore, including OCB in the reward system will make the separation between these two terms more ambiguous.

\section{Conclusion}

For a better comprehension of the relationship between OCB and knowledge sharing, it needs to be probed in terms of the dimensions of OCB, because all behaviors performed as a part of OCB require putting knowledge sharing into practice. Voluntary behaviors representing examples of "altruism" such as contributing to overcoming hard work or taking part in group work cannot be performed without knowledge sharing. Behaviors in terms of "conscientiousness" such as making constructive suggestions in order to solve problems will not be yielded without knowledge sharing. For behaviors representing "courtesy" such as informing the relevant people, cooperating with other employees to take place, knowledge sharing is essential. "Civic virtue", which involves behaviors intended for protecting the benefits of the organization at the highest level, also requires highest participation in organizational life. Boosting knowledge sharing is the way to ensure them at the top level. Developing knowledge sharing among employees in order to ensure active participation for the benefit of the organization is one of the fundamental requirements. "Sportsmanship", on the other hand, involves the behaviors intended for being sensitive to the inconveniences, constraints and extra efforts that may result from the professional processes, and avoiding organizational conflicts that may arise. In order to produce resolutions to these problems, employees need to make knowledge sharing common and functional.

Organizational knowledge sharing is a considerably important element in terms of ensuring cooperation 
among employees, developing awareness for taking responsibility, and enhancing the commitment toward the values of the organization. As knowledge sharing becomes common in an organization, manifestation of organizational citizenship behaviors by employees can be expected to increase. In fact, considering the two terms as interlocked to each other will be a better approach. In other words, in organizations where OCB is common, actions as part of knowledge sharing will most probably be common, too.

\section{References}

Aslan, Ş. (2008). Örgütsel vatandaşlık davranışı ile örgütsel bağlılık arasındaki ilişkilerin araştırılması. Yönetim ve Ekonomi, 15(2), 163-178.

Bateman, T. S., \& Organ, D. W. (1983). Job satisfaction and the good soldier: the relationship between affect and employee citizenship. Academy of Management Journal, 26(4), 587-595.

Bergeron, D. M. (2007). The potential paradox of organizational citizenship behavior: Good citizens at what cost? Academy of Management Review, 32(4), 1078-1095.

Blakely, G. L., Andrews, M. C., \& Fuller, J. (2003). Are chameleons good citizens? A longitudinal study of the relationship between self monitoring and organizational citizenship behavior, Journal of Business and Psychology, 18(2), 131-144.

Boiral, O. (2009). Greening the corporation through organizational citizenship behaviors. Journal of Business Ethics, 87, $221-236$.

Bolat, O. İ., \& Bolat, T. (2008). Otel işletmelerinde örgütsel bağlılık ve örgütsel vatandaşlık davranışı ilişkisi. Balıkesir Üniversitesi Sosyal Bilimler Enstitüsü Dergisi, 11(19), 75-94.

Bolino, M. C., Turnley, W. H., \& Bloogood, J. M. (2002). Citizenship behaviour and the creation of social capital in organizations. Academy of Management Review, 27(4), 505-522.

Bratianu, C., \& Orzea, I. (2010). Tacit knowledge sharing in organizational knowledge dynamics. Management, Marketing Challenges for Knowledge Society, 5(3), 41-62.

Cabrera, E. F., \& Cabrera, A. (2005). Fostering knowledge sharing through people management practices. International Journal of Human Resource Management, 16(5), 270-735.

Çetin, M. Ö. (2004). Örgütsel vatandaşlık davranışı. Nobel Yayın Dă̆ıtım, Ankara.

Cheah, W. C., Ooi, K. B., Teh, P. L., Chong, Y. L., \& Yong, C. C. (2009). Total quality management and knowledge sharing: comparing Malaysia's manufacturing and service organizations. Journal of Applied Sciences, 9(8), 1422-1431.

Chen, C. C., \& Chiu, S. F. (2009). The mediating role of job involvement in the relationship between job characteristics and organizational citizenship behavior. The Journal of Social Psychology, 149(4), 474-494.

Chow, C. W., Ho, J. L., \& Vera-Muñoz, S. C. (2008). Exploring the extent and determinants of knowledge sharing in audit engagement. Asia-Pacific Journal of Accounting \& Economics, 15, 141-160.

Connelly, C. E., \& Kelloway, E. K. (2003). Predictors of employees' perceptions of knowledge sharing cultures. Leadership and Organizational Development Journal, 24(5), 294-301.

Farh, J. L., Zhong, C. B., \& Organ, D. W. (2004). Organizational citizenship behavior in the people's republic of china, Organization Science, 15(2), 241-253.

Gagné, M. (2009). A model of knowledge-sharing motivation. Human Resource Management, 48(4), 571-589.

Hendriks, P. (1999). Why share knowledge? The influence of ICT on the motivation for knowledge sharing. Knowledge Process Management, 6(2), 91-100.

Ipe, M. (2003). Knowledge sharing in organizations: A conceptual framework. HRM Development Review, 2(4), $337-359$.

Jahangir, N., Akbar, M. M., \& Haq, M. (2004). Organizational citizenship behavior: Its nature and antecedents. BRAC University Journal, 1(2), 75-85.

Kankanhalli, A., Tan, B. C. Y., \& Wei, K. K. (2005). Contributing knowledge to electronic knowledge repositories: An empirical investigation. MIS Quarterly, 29(1), 113-143.

Karaaslan, A., Ergün, Ö. D., \& Kulaklığlu, A. S. (2009). Örgütsel vatandaşlık davranışı ve bilgi paylaşımı arasındaki ilişkiye yönelik bir araştırma. Afyon Kocatepe Üniversitesi, İ̈BF Dergisi, XI(II), 135-160.

Koys, D. J. (2001). The effects of employee satisfaction, organizational citizenship behavior, and turnover on organizational effectiveness: A unit-level, longitudinal study. Personnel Psychology, 54, 101-114.

Li, Z. H., Zhu, T., \& Luo, F. (2010). A study on the influence of organizational climate on knowledge-sharing behavior in IT enterprises. Journal of Computers, 5(4), 508-515. 
Liao, S. H., Chang, J. C., Cheng, S. C., \& Kuo, C. M. (2004). Employee relationship and knowledge sharing: A case study of a Taiwanese finance and securities firm. Knowledge Management Research and Practice, 2, 24-34.

Lin, C. P. (2008). Clarifying the relationship between organizational citizenship behaviors, gender, and knowledge sharing in workplace organizations in Taiwan. Journal of Business and Psychology, 22, 241-250.

Messer, B. A. E., \& White, F. A. (2006). Employees' mood, perceptions of fairness, and organizational citizenship behavior. Journal of Business and Psychology, 21(1), 65-82.

Mogotsi, I. C. (2009). An empirical investigation into the relationships among knowledge sharing behavior, organizational citizenship behavior, job satisfaction and organizational commitment (Ph.D. thesis, University of Pretoria).

Moorman, R. H., Niehoff, B. P., \& Organ, D. W. (1993). Treating employees fairly and organizational citizenship behaviors: Sorting the effects of job satisfaction, organizational commitment, and procedural justice. Employee Responsibilities and Rights Journal, 6, 209-225.

Nita, B. (2008). Identifying organizational and interpersonal relationship factors that promote knowledge sharing (Ph.D. thesis, San Diego Alliant International University).

Organ, D. W. (1988). Organizational citizenship behavior: The good soldier syndrome. Lexington: Lexington Books.

Organ, D. W., Podsakoff, P. M., \& MacKenzie, S. B. (2006). Organizational citizenship behavior: Its nature, antecedents, and consequences. Beverly Hills: Sage, CA.

Podsakoff, P. M., Mackenzie, S. B., Paine, J. B., \& Bachrach, D. G. (2000). Organizational citizenship behaviors: A critical review of the theoretical and empirical literature and suggestions for future research. Journal of Management, 26(3), 513-563.

Riege, A. (2005). Three-dozen knowledge-sharing barriers managers must consider. Journal of Knowledge Management, 9(3), 18-35.

Sezgin, F. (2005). Örgütsel vatandaşlık davranışları: kavramsal bir çözümleme ve okul açısından bazı çıkarımlar. Gazi Üniversitesi, Gazi Eğitim Fakültesi Dergisi, 25(1), 317-339.

Smalla, C. T., \& Sage, A. P. (2005/2006). Knowledge management and knowledge sharing: A review. Information Knowledge Systems Management, 5, 153-169.

Smith, C. A., Organ, D. W., \& Near, J. P. (1983). Organizational citizenship behavior: Its nature and antecedents. Journal of Applied Psychology, 68(4), 655-663.

So, J. C. F., \& Bolloju, N. (2005). Explaining the Intentions to share and reuse knowledge in the context of it service operations. Journal of Knowledge Management, 9(6), 30-41.

Spitzmuller, M., Dyne, L. V., \& Ilies, R. (2008). Organizational citizenship behavior: A review and extension of its nomolojical network. Handbook of Organizational Behavior.

Tayyab, S. (2005). Organisational citizenship behaviour: Validating factorial structure and invariance among employees. Journal of the Indian Academy of Applied Psychology, 31(1-2), 49-64.

Vries, R. E., Hooff, B. V., \& Ridder, J. A. (2006). Explaining knowledge sharing the role of team communication styles, job satisfaction, and performance beliefs. Communication Research, 33(2), 115-135.

Wech, B. A. (2002). Trust context: effect on organizational citizenship behavior, supervisory fairness, and job satisfaction beyond the influence of leader-member exchange. Business and Society, 41(3), 353-360.

Williams, L. J., \& Anderson, S. E. (1991). Job satisfaction and organizational commitment as predictors of organizational citizenship and in-role behaviors. Journal of Management, 17(3), 601-617.

Yener, M., \& Aykol, S. E. (2009). Girişimcilik değerleri ve ÖVD üzerine bir inceleme. Süleyman Demirel Üniversitesi İktisadi ve Ídari Bilimler Fakültesi Dergisi, 14(1), 255-271.

Yücel, C., \& Samanci, G. (2009). Örgütsel güven ve örgütsel vatandaşlık davranışı. Fırat Üniversitesi Sosyal Bilimler Dergisi, 19(1), 113-132.

Zellars, K. L., Teper, B. J., \& Duffy, M. K. (2002). Abusive supervision and subordinates' organizational citizenship behavior. Journal of Applied Psychology, 87(6), 1068-1076. 